\title{
Distinct U Wave Changes in Patients With Catecholaminergic Polymorphic Ventricular Tachycardia (CPVT)
}

\author{
Yoshiyasu Aizawa, ${ }^{1}$ MD, Satoru Komura, ${ }^{1}$ MD, Shinsuke OKadA, ${ }^{1}$ MD, \\ Masaomi CHINUSHI, ${ }^{1} \mathrm{MD}$, Yoshifusa AIZAwA, ${ }^{1} \mathrm{MD}$, Hiroshi MoritA, ${ }^{2} \mathrm{MD}$, \\ and Tohru OHE, ${ }^{2} \mathrm{MD}$
}

\section{SUMMARY}

Although catecholaminergic polymorphic ventricular tachycardia (CPVT) is associated with fatal ventricular arrhythmias and sudden death, the ECG findings are not fully understood. In this paper, we report on alterations in the U-wave.

Seven patients from 6 families with CPVT in which bidirectional tachycardia and polymorphic VT were induced by exercise or isoproterenol infusion visited our hospitals. VT was not inducible by programmed electrical stimulation. A novel gene mutation of the ryanodine receptor 2 (RyR2) was confirmed in 2 families.

In one of these patients, U-wave alternans was observed following ventricular pacing at 160 beats/min. In the other patient, U-wave alternans was observed during the recovery phase after the exercise stress test, which was terminated because of polymorphic VT. In both cases, leads $\mathrm{V}_{3}-\mathrm{V}_{5}$ were the leads showing alternans most clearly. In the third patient, a negative $U$-wave became positive following a pause from sinus arrest and a change in T-wave was also noted.

Since such findings were not found in the other subjects who underwent electrophysiologic study, isoproterenol infusion or exercise stress testing, the phenomenon seems to be relevant to the underlying pathogenesis of CPVT. The genesis and significance of Uwave alteration need to be determined. (Int Heart J 2006; 47: 381-389)

Key words: Bidirectional ventricular tachycardia, Mutation, Ryanodine receptor

THE U-wave is normally recognized as a low amplitude wave following a Twave, however, its genesis or origin remains controversial. ${ }^{1-4)}$ There are clinical settings in which abnormal $\mathrm{U}$-waves can be observed: prominent $\mathrm{U}$-waves in hypokalemia, ${ }^{5)}$ inverted U-waves in myocardial ischemia, ${ }^{6-8)}$ ventricular hypertrophy or dilatation, ${ }^{9,10)}$ or alteration in the amplitude in ischemic heart disease or in idiopathic ventricular tachycardia. ${ }^{11)}$

\footnotetext{
From the ${ }^{1}$ Division of Cardiology, Niigata University Graduate School of Medical and Dental Sciences, Niigata, and ${ }^{2}$ Department of Cardiology, Okayama University Graduate School of Medical and Dental Science, Okayama, Japan.

Address for correspondence: Yoshifusa Aizawa, MD, Division of Cardiology, Niigata University Graduate School of Medical and Dental Sciences, 757, Asahimachi-dori, Niigata City, Niigata 951-8510, Japan.

Received for publication November 28, 2005.

Revised and accepted February 3, 2006. 
Recently, we experienced 7 patients with catecholaminergic polymorphic ventricular tachycardia (CPVT), which is one of the primary electrical diseases of the heart and associated with fatal ventricular arrhythmias. ${ }^{12,13)}$ Gene mutation in the cardiac ryanodine receptor (RyR2) has been confirmed in $50 \%$ of patients. ${ }^{14-17)}$ The mechanism of ventricular tachyarrhythmias in CPVT is considered to be a triggered activity due to delayed afterdepolarization (DAD) ${ }^{18-21)}$ DAD is known to be augmented if intracellular calcium overload occurs in the presence of an abnormal ryanodine receptor. ${ }^{14,19-21)}$

Altered calcium cycling is now believed to result in alteration of repolarization and T-wave alternans and T-wave alternans is established as a strong predictor of arrhythmogenic risk, ${ }^{22-24)}$ but such an ECG marker of repolarization has not yet been evaluated in CPVT in which abnormal calcium cycling is highly possible. ${ }^{17-21,25)}$

We observed macroscopic alteration in the U-wave: alternans in 2 patients and a change in the polarity after a pause among 7 patients with CPVT.

\section{MeTHODS}

Patients: Seven patients were referred to Niigata University Hospital and Okayama University Hospital for further evaluation of ventricular tachyarrhythmias. All patients had polymorphic ventricular tachycardia and bidirectional ventricular tachycardia with or without ventricular fibrillation. All of these arrhythmias were induced by exercise or by infusion of isoproterenol (Table). Routine examinations excluded structural heart diseases or ischemic heart disease. The ventricular tachycardias were not induced by programmed electrical stimulation. ${ }^{26}$ ) Of these, 2 de novo mutations were confirmed in 3 patients from 2 families as reported elsewhere. ${ }^{15,16)}$

Table. Clinical and ECG Profiles of Patients With CPVT

\begin{tabular}{cccccrl}
\hline Case & Age/Sex & Syncope & HR (bpm) & QT (msec) & U (mV) & $\begin{array}{l}\text { Arrhythmias } \\
\text { documented }\end{array}$ \\
\hline 1 & $20 / \mathrm{M}$ & + & 46 & 440 & 0.1 & BVT/PVT* \\
2 & $23 / \mathrm{F}$ & - & 60 & 420 & $<0.1$ & PVT* $^{*}$ \\
3 & $17 / \mathrm{M}$ & - & 43 & 450 & 0.2 & BVT/PVT* $^{*}$ \\
4 & $34 / \mathrm{F}$ & - & 50 & 400 & 0.2 & PVT* $^{*}$ \\
5 & $23 / \mathrm{F}$ & + & 55 & 440 & $<0.1$ & PVT** $^{*}$ \\
6 & $57 / \mathrm{F}$ & + & 53 & 420 & 0.3 & PVT** $^{* *}$ \\
7 & $30 / \mathrm{M}$ & + & 56 & 360 & 0.5 & PVT* $^{* *}$ \\
\hline
\end{tabular}

BVT indicates bidirectional ventricular tachycardia and PVT, polymorphic ventricular tachycardia.

*:arrhythmias induced by isoproterenol infusion. **: arrhythmias induced in exercise test on treadmill or two-step test. Case 7 is the son of case 6 . 
ECG findings: The ECGs of 7 patients had normal PR and QT intervals as well as QRS complexes but they showed a relatively slow heart rate (43-60 beats/ min.) The U-wave was within the normal range in all patients (Table).

The first patient was a 20-year-old male (case 1) and polymorphic ventricular tachycardia and ventricular fibrillation were induced on exercise at another hospital and DC shock was used to restore sinus rhythm. He visited Niigata University Hospital for further evaluation.

His resting ECG was normal (Figure 1A) and other examinations resulted in normal findings. No ventricular arrhythmia was induced in an electrophysiologic study by programmed ventricular stimulation, but infusion of isoproterenol induced frequent premature ventricular beats and bidirectional ventricular tachycardia as shown in Figures 1B and 1C.

The ECG was normal and showed a normal U-wave without alternation in the control state (Figure 2A). In an electrophysiologic study, rapid ventricular

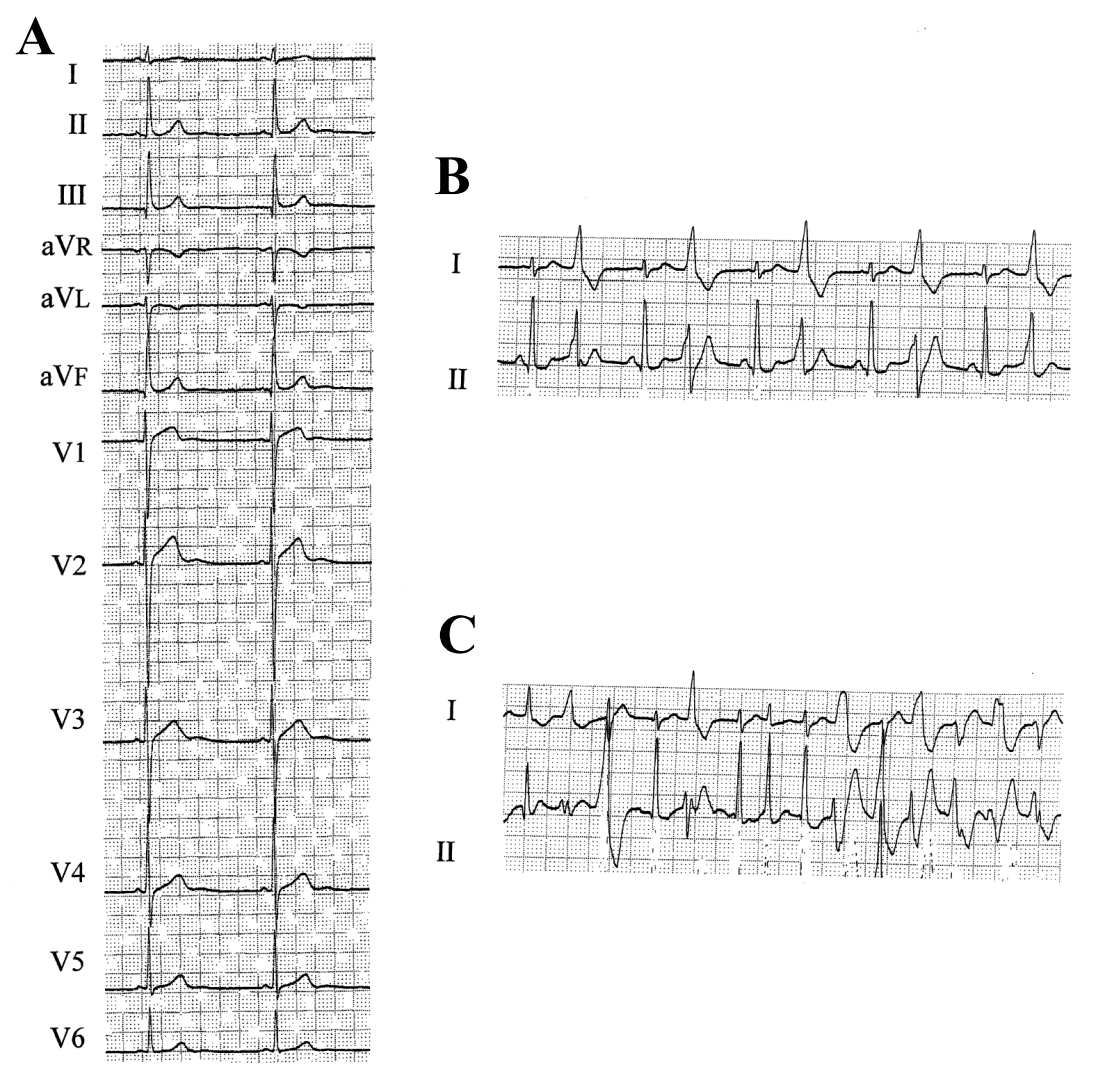

Figure 1. ECG of a patient with catecholaminergic polymorphic ventricular tachycardia.

The patient was case 1. A: 12 lead ECG shows entirely normal tracing. B: Infusion of isoproterenol in an electrophysiologic study induced a ventricular premature beat, which was followed by poly or bidirectional ventricular tachycardia as shown in $\mathbf{C}$. 


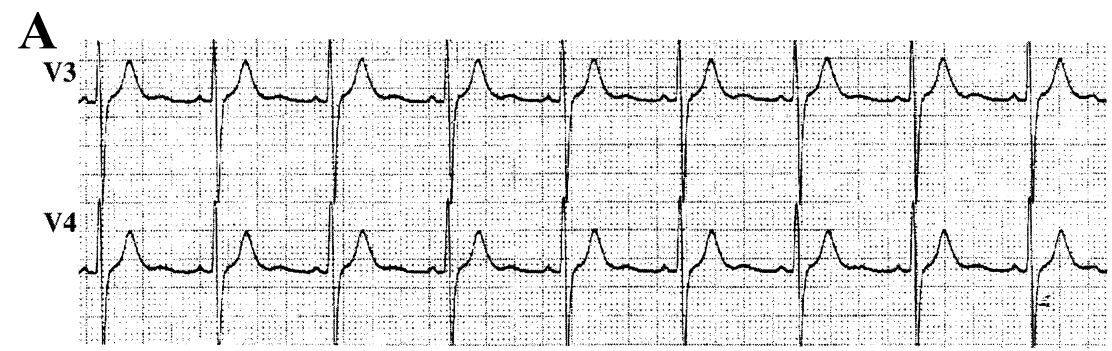

B

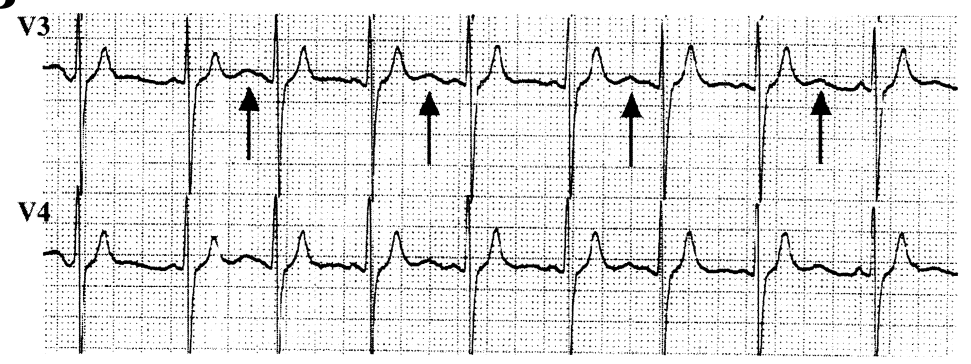

Figure 2. U-Wave Alternans.

Same patient as in Figure 1. A: Before the ventricular pacing, a small but stable U wave can be seen. Rapid ventricular pacing was performed for 10 seconds up to 210 beats/min to induce VT. B: After ventricular pacing at 160 beats/min, U-wave alternans can be clearly seen in $V_{3}$ and $V_{5}$. The $R R$ interval showed variations but the alternans was not related to the varying preceding RR interval.

pacing was attempted at progressively higher rates and immediately after pacing at 160 beats/min for 10 seconds, an alternating U-wave was found in the precordial leads (Figure 2B). The RR interval showed a slight variation but the amplitude of the U-wave was not closely related to the variation of the RR interval. After rapid pacing at lower or higher rates, such alternation was not evident. A novel mutation was confirmed in the ryanodine receptor as reported elsewhere. ${ }^{15)}$

The second patient was a 23-year-old female (case 2) and her resting ECG was noncontributory: sinus rhythm at 60 beats/min with normal PR and QT and a normal U-wave. She was referred to Okayama University Hospital. During twostep exercise testing, a polymorphic ventricular tachycardia was induced (Figure $3 \mathrm{~A})$ and exercise was stopped. Five minutes after the cessation of exercise, Uwave alternans was observed in the precordial leads, $\mathrm{V}_{3}-\mathrm{V}_{6}$ (Figure 3B). Though the RR interval varied a little, the amplitude of the U-wave was not related to the varying preceding RR interval. The phenomenon was transient and an ECG 8 minutes after exercise showed no alternans of the U-wave.

The third patient was a 57-year-old female (case 6 and the mother of case 7). She developed palpitations and syncope on exertion and Holter ECG showed frequent polymorphic ventricular tachycardia (Figure 4A). There was a history of sudden cardiac death in the family and a novel mutation was found in the ryano- 


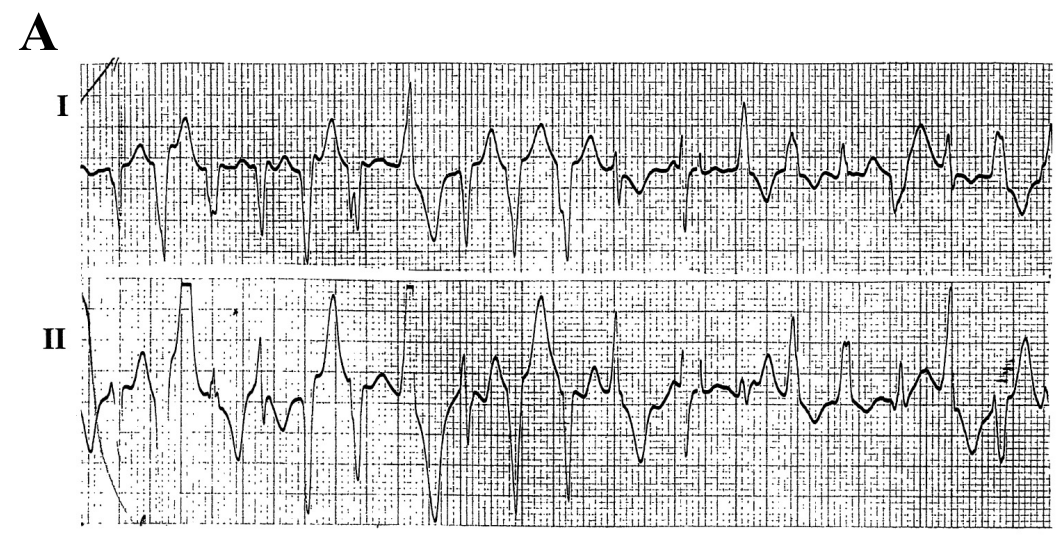

B

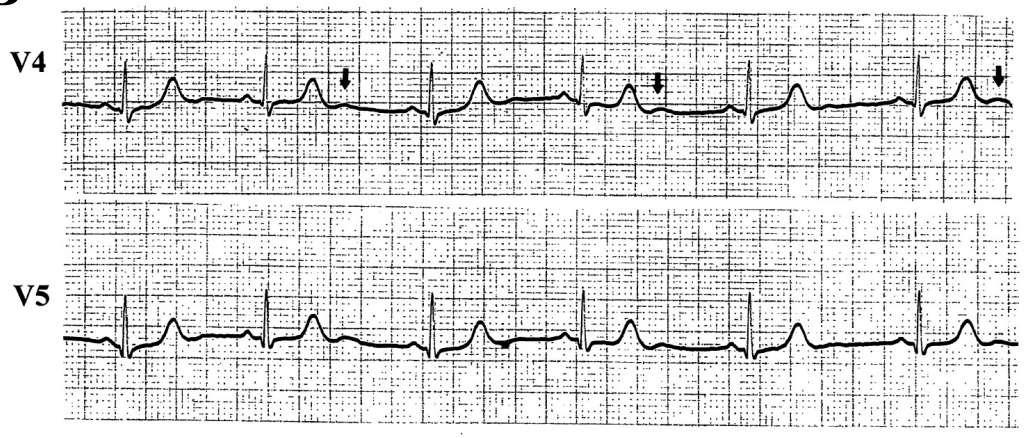

Figure 3. ECG of a patient with catecholaminergic polymorphic ventricular tachycardia.

The patient was case 2 and polymorphic ventricular tachycardia was easily induced by two-step exercise testing (A). It disappeared soon after cessation of the exercise and at 5 minutes into the recovery phase, $\mathrm{U}$ wave alternans was observed in the precordial leads (B). They were most clearly in $\mathrm{V}_{3}-\mathrm{V}_{5}$.

dine receptor. ${ }^{13)}$ She was treated with beta-blockers which suppressed exercise induced ventricular arrhythmia, but only partially, and she was referred to Niigata University Hospital for further evaluation. Routine examinations were normal and structural heart disease was not found. The coronary angiography performed at another hospital was normal.

Her ECG showed normal tracing except for the negative U-wave in precordial leads $\mathrm{V}_{4}$ to $\mathrm{V}_{6}$. An intermittent pause during continuous tracing was due to sinus arrest or arrhythmia (Figure 4B). The beat following a pause showed a positive U-wave which returned as a negative one within 5-6 beats. This pause dependent change in the polarity of the U-wave was reproducible and a concomitant change in the T-wave was observed. 


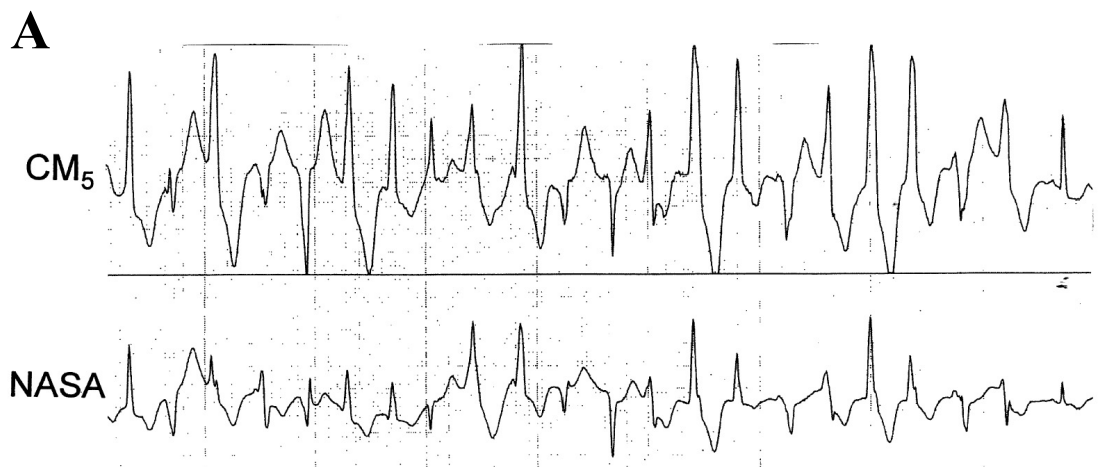

B

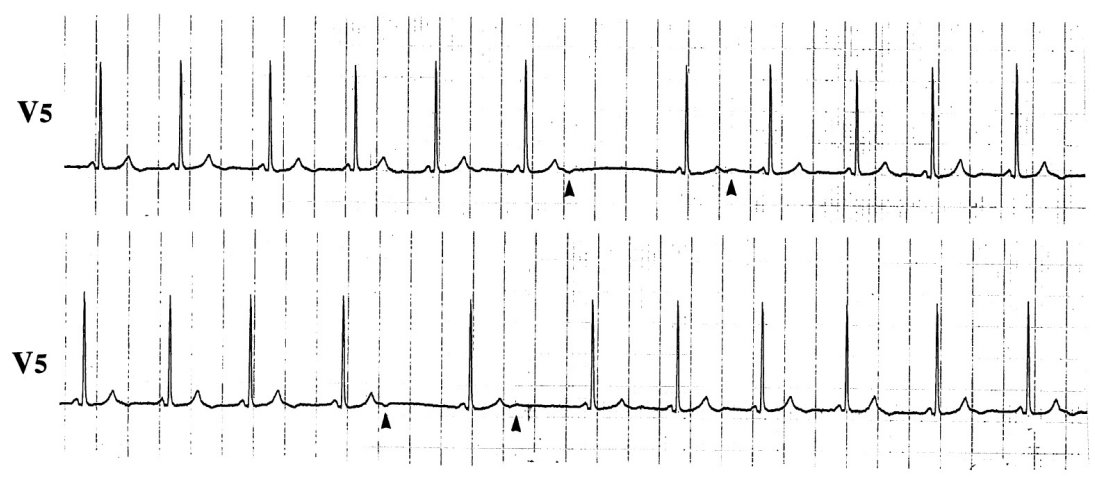

Figure 4. Pause-dependent change in U-Wave polarity.

The patient was a female (case 6). A: Holter ECG showed polymorphic ventricular tachycardia on exercise. She had been treated with a beta-blocker and then visited our hospital. Her ECG showed intermittent prolongation of the RR interval because of sinus arrest or sinus arrhythmia (B). Negative U-wave was clearly seen in the precordial leads but immediately after a pause, it became positive and returned to being negative in 5-6 beats (upper). Following sinus arrhythmia, it became less negative (lower). A gradual change in the T-wave was also noted. CM5/NASA: Standard leads used in Holter ECG.

\section{DISCUSSION}

CPVT is a primary electrical disease of the heart and is associated with fatal ventricular arrhythmias. ${ }^{12-15)}$ The ventricular arrhythmias are precipitated by emotional and physical stress and recent genetic studies have shown a mutation in RyR2. ${ }^{14-16,18)}$

The mutation of RyR2 in CPVT has been shown to increase the probability of the Ca-channel of sarcoplasmic reticulum opening, leading to intracellular $\mathrm{Ca}$ overloading, ${ }^{18-21)}$ and the ventricular arrhythmias found in CPVT are believed to be due to a triggered activity. ${ }^{17,18)}$ However, there is no marker in the surface ECG 
or in an electrophysiologic study predicting the arrhythmogenic risk in CPVT.

All 7 patients studied at the 2 institutions (Niigata University Hospital and Okayama University Hospital) could be diagnosed as CPVT. Of note, we found unexpected changes in the U-wave in 3 of the 7 patients: U-wave alternans in 2 patients and a change in the polarity of the inverted $\mathrm{U}$-wave after a pause in 1 patient. The pause-dependent change in U-wave polarity was associated with a change in the T-wave.

Changes in the amplitude of the U-wave might be observed in some patients with ischemic heart disease during exercise stress testing ${ }^{6,8)}$ or following a pause after premature ventricular contraction in patients with idiopathic ventricular tachycardia ${ }^{11)}$ or long QT syndrome, ${ }^{27)}$ but alternans of the U-wave has not been reported. Similarly, though an inverted U-wave is considered as a hallmark for the presence of myocardial ischemia or hypertrophy, ${ }^{6-10)}$ a prompt change after a pause has not been previously reported as found in the present study. The mechanism and the significance of such peculiar changes in the U-wave need to be determined.

Macroscopic T-wave alternans is often observed in heart failure patients ${ }^{28)}$ or in patients with long QT syndrome ${ }^{27)}$ and is associated with a poor prognosis and can be a marker of arrhythmogenic risk. Furthermore, microvoltage T-wave alternans, which is a heart rate-dependent measure of repolarization, ${ }^{22)}$ has been shown to be a strong predictor of spontaneous ventricular arrhythmias or death. ${ }^{22-24)}$

T-wave alternans has been shown to result from alteration of cardiac repolarization at the cellular level, and the heart rate at which myocytes exceed the capacity to cycle intracellular $\mathrm{Ca}^{2+}$ is crucial for T-wave alternans to develop. ${ }^{29,30}$ In a single cell, ${ }^{25}$ a tissue sample, ${ }^{31)}$ and in the intact heart, ${ }^{32)} \mathrm{T}$-wave alternans has now been shown to be closely associated with intercellular $\mathrm{Ca}$ cycling rather than action potential duration restitution.

Since the release of calcium from sarcoplasmic reticulum has been shown to promote both intercellular $\mathrm{Ca}^{2+}$ alternans and action potential duration alternans, ${ }^{25)} \mathrm{T}$-wave alternans might be expected to occur very often in CPVT, however, this has not yet been proven. The relation between the abnormal $\mathrm{Ca}^{2+}$ cycling and U-wave alternans needs to be determined in the future.

In summary, we have presented 3 patients with CPVT who showed U-wave alternans or a sudden change in the U-wave polarity after a pause. Altered intracellular calcium cycling in CPVT may be related to such peculiar ECG findings, however, its pathogenesis or relation to arrhythmogenicity needs to be studied further. 


\section{REFERENCES}

1. Lepeschkin E. Physiologic basis of the U waves. In: Schlant RC and Hurst JW (eds). Advances in Electrocardiology. New York; Grune and Stratton Inc; 1972.

2. Ritsema van Eck HJ, Kors JA, van Herpen G. The elusive U wave: a simple explanation of its genesis. J Electrocardiol 2003; 36 Suppl: 133-7.

3. Watanabe Y. Purkinje repolarization as a possible cause of the $U$ wave in the electrocardiogram. Circulation 1975; 51: 1030-7.

4. Anzelevitch C, Sicouri S. Clinical relevance of cardiac arrhythmias generated by afterdepolarization. Role of M cells in the generation of U waves, triggered activity and torsade de pointes. J Am Coll Cardiol 1994; 23: 25977. (Review)

5. Ishikawa K, Tateno M. Alternans of the repolarization wave in a case of hypochloremic alkalosis with hypopotassemia. J Electrocardiol 1976; 9: 75-9.

6. Gerson MC, Phillips JF, Morris SN, Mc Henry PL. Exercise-induced U-wave inversion as a marker of stenosis of the left anterior descending coronary artery. Circulation 1979; 60: 1014-20.

7. Fu LT, Kato N, Takahashi N. Ischaemia-induced negative U waves in electrocardiograms (an experimental study in canine hearts). Cardiovasc Res 1982; 16: 240-8.

8. Miwa K, Nakagawa K, Hirai T, Inoue H. Exercise-induced U-wave alterations as a marker of well-developed and well-functioning collateral vessels in patients with effort angina. J Am Coll Cardiol 2000; 35: 757-63.

9. Twidale N, Gallagher AW, Tonkin AM. Echocardiographic study of U wave inversion in the electrograms of hypertensive patients. J Electrocardiol 1989; 22: 365-71.

10. Pelliccia F, Critelli G, Cianfrocca C, Nigri A, Reale A. Electrocardiographic correlates with left ventricular morphology in idiopathic dilated cardiomyopathy. Am J Cardiol 1991; 68: 642-7.

11. Nakagawa M, Ooie T, Hara M, et al. Dynamics of T-U wave in patients with idiopathic ventricular tachycardia originating from the right ventricular outflow tract. Pacing Clin Electrophysiol 2004; 27: 148-55.

12. Leenhardt A, Lucet V, Denjoy I, Grau F, Ngoc DD, Coumel P. Catecholaminergic polymorphic ventricular tachycardia in children. A 7-year follow-up of 21 patients. Circulation 1995; 91: 1512-9.

13. Sumitomo N, Harada K, Nagashima M, et al. Catecholaminergic polymorphic ventricular tachycardia: electrocardiographic characteristics and optimal therapeutic strategies to prevent sudden death. Heart 2003; 89: 66-70.

14. Priori SG, Napolitano C, Memmi M, et al. Clinical and molecular characterization of patients with catecholaminergic polymorphic ventricular tachycardia. Circulation 2002; 106: 69-74.

15. Aizawa Y, Ueda K, Komura S, et al. A novel mutation in FKBP12.6 binding region of the human cardiac ryanodine receptor gene $(\mathrm{R} 2401 \mathrm{H})$ in a Japanese patient with catecholaminergic polymorphic ventricular tachycardia. Int J Cardiol 2005; 99: 343-5.

16. Aizawa Y, Miyoshi F, Kobayashi Y, et al. Genetic study of cardiac ryanodine receptor (RyR2) in Japanese patients with catecholaminergic polymorphic ventricular tachycardia and arrhythmogenic right ventricular dysplasia. Cir J 2005; 69 (Suppl I): 366. (Abstract)

17. Wehrens XH, Lehnart SE, Huang F, et al. FKBP12.6 deficiency and defective calcium release channel (ryanodine receptor) function linked to exercise-induced sudden cardiac death. Cell 2003; 113: 829-40.

18. Marks AR, Priori S, Memmi M, Kontula K, Laitinen PJ. Involvement of the cardiac ryanodine receptor/calcium release channel in catecholaminergic polymorphic ventricular tachycardia. J Cell Physiol 2003; 190: 1-6. (Review)

19. Tweedie D, Harding SE, MacLeod KT. Sarcoplasmic reticulum Ca content, sarcolemmal Ca influx and the genesis of arrhythmias in isolated guinea-pig cardiomyocytes. J Moll Cell Cardiol 2000; 32: 261-72.

20. George CH, Higgs GV, Lai FA. Ryanodine receptor mutations associated with stress-induced ventricular tachycardia mediate increased calcium release in stimulated cardiomyocytes. Circ Res 2003; 93: 531-40.

21. Nam GB, Burashnikov A, Antzelevitch C. Cellular mechanisms underlying the development of catecholaminergic ventricular tachycardia. Circulation 2005; 111: 2727-33.

22. Rosenbaum DS, Jackson LE, Smith JM, Garan H, Ruskin JN, Cohen RJ. Electrical alternans and vulnerability to ventricular arrhythmias. N Engl J Med 1994; 330: 235-41.

23. Gold MR, Bloomfield DM, Andersen KP, et al. A comparison of T-wave alternans, signal averaged electrocardiography and programmed ventricular stimulation for arrhythmia risk stratification. J Am Coll Cadiol 2000; 
36: $2247-53$.

24. Ikeda T, Sakata T, Takami M, et al. Combined assessment of T-wave alternans and late potentials used to predict arrhythmic events after myocardial infarction. A prospective study. J Am Coll Cardiol 2000; 35: 722-30.

25. Huser J, Wang YG, Sheehan KA, Cifuentes F, Lipsius SL, Blatter LA. Functional coupling between glycolysis and excitation-contraction coupling underlies alternans in cat heart cells. J Physiol 2000: 524: 795-806.

26. Aizawa Y, Niwano S, Chinushi M, et al. Incidence and mechanism of interruption of reentrant ventricular tachycardia with rapid ventricular pacing. Circulation 1992; 85: 589-95.

27. Viskin S, Heller K, Barron HV, et al. Postextrasystolic U wave augmentation, a new marker of increased arrhythmic risk in patients without the long QT syndrome. J Am Coll Cardiol 1996; 28: 1746-52.

28. Kodama M, Kato K, Hirono S, et al. Linkage between mechanical and electrical alternans in patients with chronic heart failure. J Cardiovasc Electrophysiol 2004; 15: 295-9.

29. Spear JF, Moore EN. A comparison of alternation in myocardial action potentials and contractility. Am J Physiol 1971; 220: 1708-16.

30. Hirayama Y, Saitoh H, Atarashi H, Hayakawa H. Electrical and mechanical alternans in canine myocardium in vivo. Dependence on intracellular calcium cycling. Circulation 1993; 88: 2894-902.

31. Laurita KR, Katra R, Wible B, Wan X, Koo MH. Transmural heterogeneity of calcium handling in canine. Cir Res 2003; 92: 668-75.

32. Pruvot EJ, Katra RP, Rosenbaum DS, Lauria KR. Role of calcium cycling versus restitution in the mechanism of repolarization alternans. Cir Res 2004; 94: 1083-90. 